Review began 10/08/2021 Review ended 10/12/2021 Published 10/14/2021

() Copyright 2021

Alrahili et al. This is an open access article distributed under the terms of the Creative Commons Attribution License CC-BY 4.0. which permits unrestricted use, distribution, and reproduction in any medium, provided the original author and source are credited.

\section{The Association Between Screen Time Exposure and Autism Spectrum Disorder-Like Symptoms in Children}

Nader Alrahili ${ }^{1}$, Najla A. Almarshad ${ }^{1}$, Reham Y. Alturki ${ }^{2}$, Jamal S. Alothaim ${ }^{1}$, Roba Mohsin Altameem ${ }^{1}$, Mohammed A. Alghufaili ${ }^{1}$, Abdulmajeed A. Alghamdi ${ }^{1}$, Asem A. Alageel ${ }^{1}$

1. Department of Psychiatry, Imam Mohammad Ibn Saud Islamic University, Riyadh, SAU 2. Department of Psychiatry, King Saud University, Riyadh, SAU

Corresponding author: Jamal S. Alothaim, jamal.alothaim.1@gmail.com

\section{Abstract}

\section{Research problem}

Advances in technology have ensured its inevitable integration in our life. Children, being at a vulnerable age period of development, are spending more time on electronic devices. Some studies reported negative effects on sleep, physical health such as obesity and vision problems, and behavioral changes such as aggressive behavior with exposure to violent media content.

\section{Research significance}

We will study the effect of using electronic devices on communication skills in children in Saudi Arabia. Our findings can be used to raise awareness on this matter.

\section{Research objectives}

The aim of our study is to examine the association between screen time and social communication skills among children of four years to six years of age in Saudi Arabia.

\section{Research methodology}

A cross-sectional study was conducted to investigate the relationship between social skills development and screen time by using a validated Arabic version of the Social Communication Questionnaire (SCQ). The sample in this study consists of 308 children from four to six years of age.

\section{Research results}

The results showed that the hours spent using the electronic device were significantly associated with having an SCQ score $\geqslant 15(\mathrm{P}<0.05)$. A high SCQ score was prevalent in $19.7 \%(\mathrm{n}=31)$ of children who spent $>3$ hours using an electronic device compared to $10.2 \%(n=5)$ and $7.84 \%(n=8)$ of children who spent an hour or $<2$ hours using electronic devices, respectively.

\section{Conclusion}

Our study highlighted a significant association between the daily hours spent on devices and having an SCO score above 15 , which suggests a deficit in social skill development and having autism spectrum disorderlike symptoms.

Categories: Pediatrics, Psychiatry

Keywords: asd-like symptoms, social skills, neurodevelopment, social media, screen time

\section{Introduction}

Advances in technology have ensured its inevitable integration in our life. Children, being at a vulnerable age period of development, are spending more time on electronic devices. Some studies have reported negative effects on sleep, physical health such as obesity and vision problems, and behavioral changes such as aggressive behavior with exposure to violent media content [1-3]. However, the benefits of using electronic devices are undeniable. To list a few, electronic devices have facilitated social communication among children in this period of repetitive lockdowns and restricted outdoor activities. In addition, it has revolutionized learning as children have easy access to educational content [3]. Hence, the American Academy of Pediatrics has made age-specific recommendations for media use by children that balance its risks and benefits.

The recommendation on screen time is for caregivers to co-watch good programs with children of $2-5$ years 
of age for a duration not exceeding one hour a day. Children above 5 years can watch alone while adhering to clear restrictions on screen time and program types that are left to the caregiver to set, avoiding negative effects on the child's sleep, behavior, or other aspects of health [4]. Similarly, the World Health Organization recommends that children of 4-6 years of age should not exceed one hour of screen time in a day [5]. The Saudi Ministry of Health makes the same recommendations as the American Academy of Pediatrics guidelines [5].

Healthcare professionals are interested in tracking developmental milestones in children, which can be divided into the following domains: motor skills, social/emotional, language/communication, and cognitive domains. In regard to social development, children of 4-6 years of age are expected to show interest in other children, play in groups, desire being liked by friends, and understand the concept of cooperation and apology [6]. In contrast, ignoring other children, being excessively shy, and failing to recognize others' feelings are considered red flags of developmental delay for ages 4,5 , and 6 years, respectively [7].

In regard to language and communication development, children of 4-6 years of age are expected to be able to tell stories and describe events [6]. If children aged 4,5 , and 6 years fail to answer simple questions, rhyme, and tell clear stories, respectively, they have probably missed a milestone [7]. We postulate that those milestones can be disturbed by increased screen time. Using the Adaptive Social Behavior Inventor, a study found that increased screen time is associated with lower social skills in preschool children [8]. Another study among preschool children found that increased screen time was associated with lower prosocial skills in boys but higher prosocial skills in girls [9].

Moreover, another study conducted among preschoolers in China indicated that the risk of autism spectrum disorder (ASD)-like symptoms increases remarkably in preschoolers whose screen time is $>2$ hours a day [10]. Another study found that early age of screen exposure increases the incidence of autistic behaviors among preschoolers [11]. A study in Japan showed that the average use of mobile phones was 24 hours per week [12].

A few studies were conducted in Saudi Arabia to identify the most used devices and determine the exposure to these devices. The most used devices are the television, followed by mobile phones and tablets then followed by Computers, In addition children use electronic devices for $>4$ hours per day [13]. Moreover, there is another study that shows that smartphones are the most common devices used by children (mean usage of $28.5 \pm 27$ hours per week), followed by tablets ( $7.5 \pm 15$ hours per week) and laptops ( $3 \pm 7.4$ hours per week). The median duration of use of all the devices together was 35 hours per week [14].

An interesting finding by a study shows that higher-quality screen exposure has been linked to better language skills, whereas higher-quantity screen exposure, introduced early in development, has been linked to lower language skills [15]. There are not enough data on the association between screen time exposure and ASD-like symptoms such as delay in language development, unusual social interactions, odd play patterns, and unusual communication patterns [16].

Our study aimed to examine the association between screen time and social communication skills among children of 4-6 years of age in Saudi Arabia and identify the factors associated with high SCQ scores.

\section{Materials And Methods}

A cross-sectional survey design was conducted to examine the relationship between social skills development and screen time using a validated Arabic version of the Social Communication Questionnaire (SCQ) [17]. The sample in this study consists of 308 children aged 4-6 years. Data were collected in two steps: first, the researchers shared a form through different social media platforms to collect personal information and contact data of interested participants. Three hundred and eight participants showed interest in participating in this study and the Social Communication Questionnaire (SCQ) was sent to them. The inclusion criteria were children aged 4-6 years. The exclusion criteria were non-Arabic-speakers and children with developmental disorders or cognitive delay. Also the aim of this study was to study the association between screen time and social communication skills among children of four years to six years of age in Saudi Arabia.

\section{Study design}

The Social Communication Questionnaire consists of 40 items. It is a parent-reported scale that can be used to screen for symptoms associated with ASD. We used a validated Arabic version of SCQ with a Cronbach's alpha coefficient of 0.916 , showing high reliability. It also showed high sensitivity and specificity of 0.796 and 0.966 , respectively. The 40 items are dichotomous, with only 'yes' and 'no' as possible answers. Item 1 is only used to assess whether the child can speak with short phrases or sentences, while Items 2 through 40 are used for the actual scoring. Items 2 , 9, and 19 through 40 are negatively worded wherein individuals are awarded 1 for response option no and 0 for yes. This reduces the need to reverse the scores. For the other items (i.e., Items 3 to 8 and 10 to 18), a score of 1 is awarded if the answer is yes and 0 otherwise. 


\section{Cureus}

\section{Statistical analysis}

Statistical analysis was performed using R v 3.6.3. Counts and percentages were used to summarize the categorical variables. The means \pm standard deviation or the median/interquartile ranges were used to summarize the distribution of normal and non-normal continuous variables, respectively. The chi-square test was used to investigate the association between categorical variables. Linear regression was used to assess the factors associated with higher total SCQ scores. Hypothesis testing was performed at $5 \%$ level of significance.

\section{Results}

\section{Descriptive statistics}

The study survey was completed by the caregivers of 308 children (39.6\% females and $60.4 \%$ males). Approximately half of the respondents were mothers (57.5\%) and 17.5\% were fathers of the children. The questionnaire was completed by brothers/sisters and aunts in $12.3 \%$ and $12.7 \%$ of the cases. Respondents aged 4,5 , and 6 years represented $34.7 \%, 26.3 \%$, and $39 \%$ of the study sample, respectively. The majority of the parents for the included children lived in the same house (91.9\%). The remaining parents were either separated $(6.17 \%)$ or widowed $(1.95 \%)$ (Table 1$)$.

\section{[ALL]}

$\mathrm{N}=308$

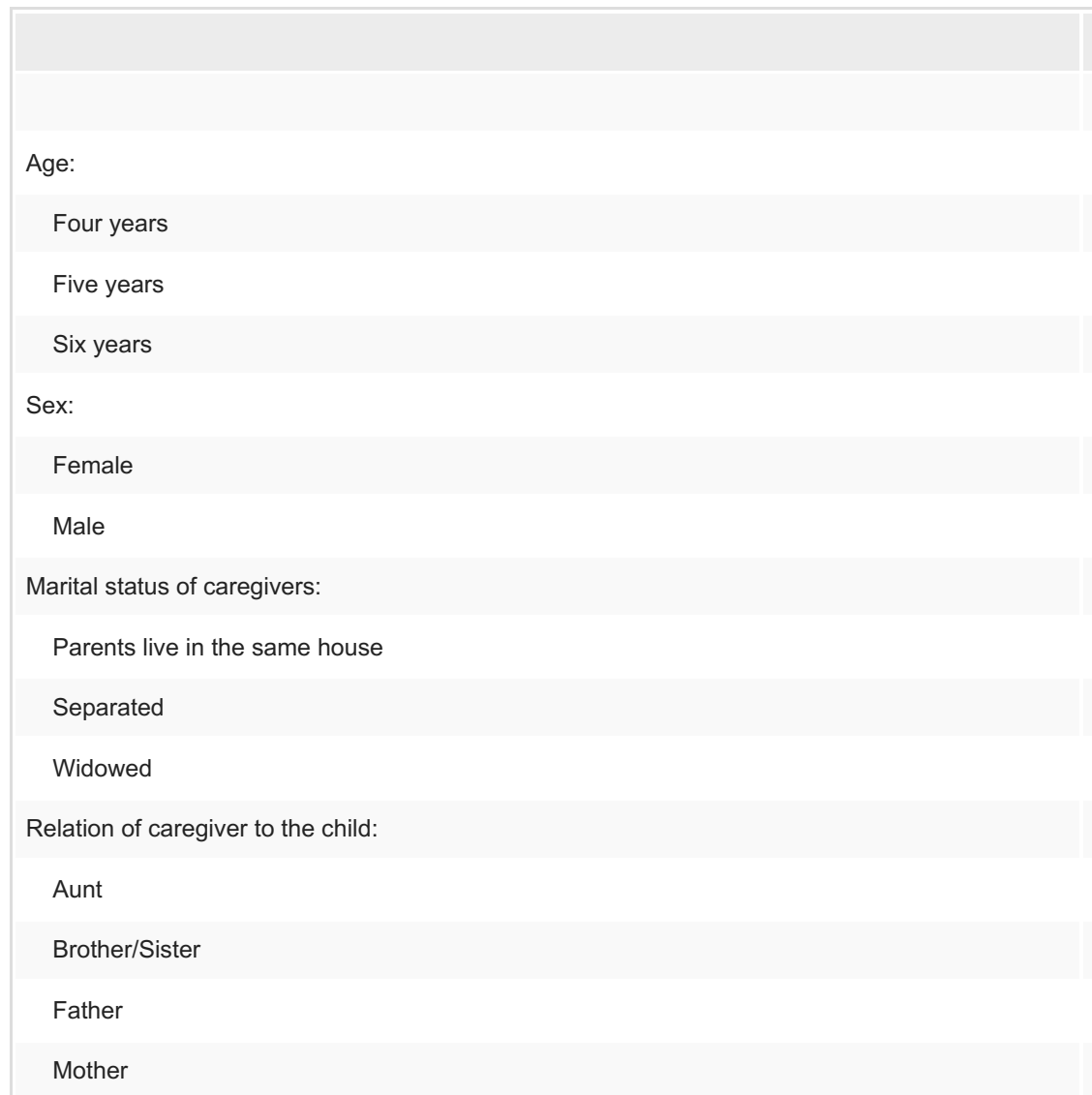

$107(34.7 \%)$

$81(26.3 \%)$

$120(39.0 \%)$

$122(39.6 \%)$

$186(60.4 \%)$

$283(91.9 \%)$

$19(6.17 \%)$

$6(1.95 \%)$

$39(12.7 \%)$

$38(12.3 \%)$

$54(17.5 \%)$

$177(57.5 \%)$

Education level of caregiver:

Bachelor's degree

$195(63.3 \%)$

High school

$26(8.44 \%)$

$3(0.97 \%)$

$66(21.4 \%)$

Post-graduate degree

$18(5.84 \%)$

Primary school

Mobile phone

$80(26.0 \%)$

Other

Tablet/iPad

$124(40.3 \%)$ 


\section{Cureus}

Television

$82(26.6 \%)$

Does the child have a personal device?

No

Shares with the family

Yes

Daily hours spent using the electronic device:

Hour or less

More than three hours

Two hours
$112(36.4 \%)$

$62(20.1 \%)$

$134(43.5 \%)$

$49(15.9 \%)$

$157(51.0 \%)$

$102(33.1 \%)$

\section{TABLE 1: Descriptive statistics for the study sample}

Regarding the education level of the caregivers, $63.3 \%$ of the respondents had completed university education, $21.4 \%$ had a postgraduate degree, and $8.44 \%$ of the respondents had completed only high school. Tablets and iPads were the main devices used by $40.3 \%$ of the children. Mobile phones and televisions were the main devices used by $26 \%$ and $26.6 \%$ of the children, respectively. Approximately half of the children had a personal device (43.5\%); less than one quarter shared devices with the family (20.1\%); and 36.4\% did not have a personal device. One-half of the respondents (51\%) spent more than three hours using the electronic device daily; one-third used it for two hours daily (33.1\%); and 15.9\% used it for an hour or less daily (Table 1).

The results showed that $20.4 \%$ of the children had problems with social chat, and $20.1 \%$ could not understand non-verbal communication. One-third of the respondents (34.1\%) were not interested in peers; a similar number did not have a best friend (32.1\%); and $40.3 \%$ did not use gestures to draw attention. Only $7.7 \%$ of the children had problems with active communication, and only $7.1 \%$ did not have a normal range of facial expressions (Figure 1).

\begin{tabular}{|c|c|}
\hline Joining in with games - & $14.9 \%$ \\
\hline Imaginative play with peers - & $26.0 \% \quad 74.0 \%$ \\
\hline Capable understanding non-verbal communication - & $20.1 \% \quad 79.9 \%$ \\
\hline Response to peers - & $22.7 \% \quad 77.3 \%$ \\
\hline Interest in peers - & $34.1 \% \quad 65.9 \%$ \\
\hline Playing fantasy/imaginary games - & $17.5 \% \quad 82.5 \%$ \\
\hline Imitative social play- & $16.9 \%$ \\
\hline Normal range of facial expression - & $7.1 \%$ \\
\hline Able to draw attention when needed - & $16.6 \%$ \\
\hline Empathy- & $18.8 \% \quad 81.2 \%$ \\
\hline Seeking to share enjoyment ${ }^{-}$ & $11.0 \% \quad 89.0 \%$ \\
\hline Offering to share - & $14.9 \% \quad 85.1 \%$ \\
\hline Showing things to seek attention - & $10.4 \% \quad 89.6 \%$ \\
\hline Returning smiles - & $12.3 \% \quad 87.7 \%$ \\
\hline Eye contact during communication - & $13.0 \% \quad 87.0 \%$ \\
\hline Shaking head for no - & $26.0 \% \quad 74.0 \%$ \\
\hline Nodding head for yes - & $21.1 \% \quad 78.9 \%$ \\
\hline Using ges tures to draw attention - & $40.3 \%$ \\
\hline Pointing to draw attention - & $28.2 \%$ \\
\hline Spontaneous imitation - & $14.0 \% \quad 86.0 \%$ \\
\hline Social chat ${ }^{-}$ & $20.4 \% \quad 79.5 \%$ \\
\hline Friends - & $32.1 \% \quad 67.9 \%$ \\
\hline Appropriate use of facial expressions - & $13.6 \% \quad 86.4 \%$ \\
\hline Active communication - & $92.3 \%$ \\
\hline & $0 \% \quad 20 \% \quad 40 \% \quad 60 \% \quad 80 \% \quad 100$ \\
\hline
\end{tabular}

FIGURE 1: Responses to SCQ items 2, 9, and 19 through 40.

SCQ: Social Communication Questionnaire

The results showed that $50.8 \%$ of the children had an awkward communication style; $45.1 \%$ used self- 


\section{Cureus}

created words; and $35 \%$ used verbal rituals. Moreover, $51.9 \%$ of the children had an unusual intensive interest in things (Figure 2).

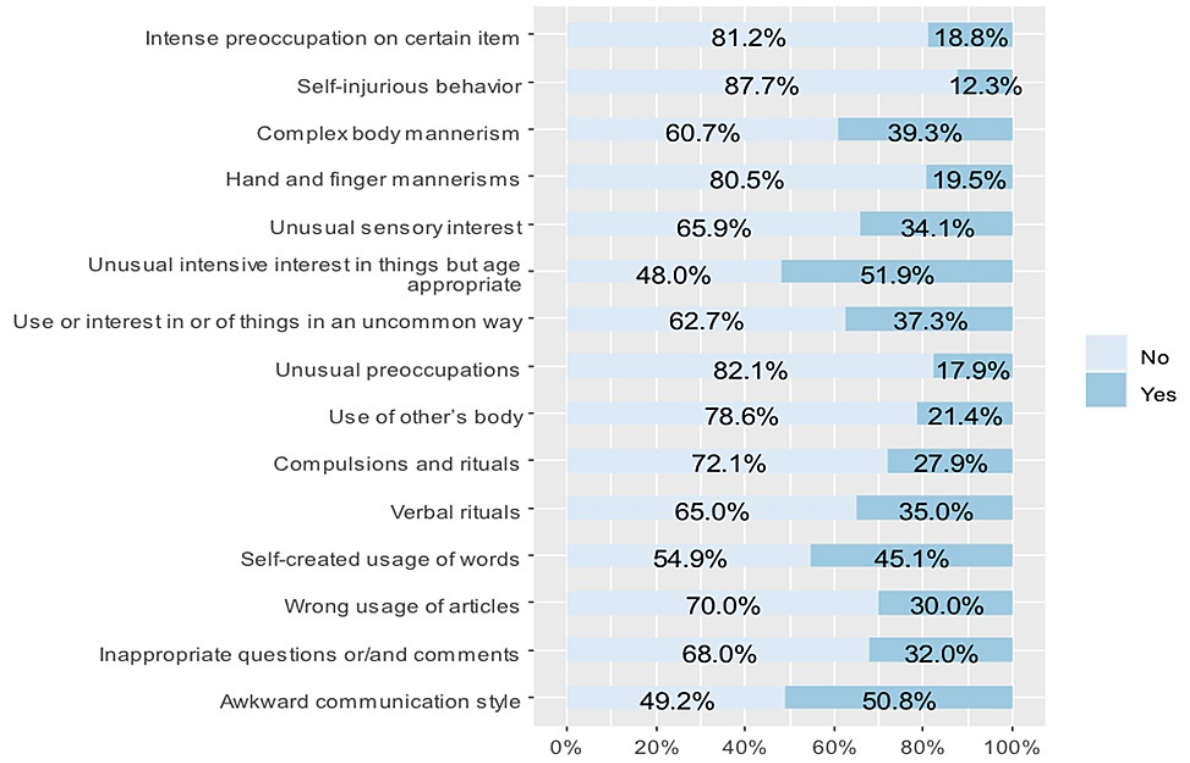

FIGURE 2: Responses to SCQ items 3 through 8 and 10 through 18.

SCQ: Social Communication Questionnaire

The average SCQ score was $9.26 \pm 5.19$, with minimum and maximum values of 0 and 30 , respectively. The distribution was fairly normal. A total of 44 (14.3\%) respondents had a high SCQ score, defined as a score $\geqslant 15$. The chi-square test was used to examine the factors associated with high SCQ scores. These factors included the sex and age of the child, hours spent using electronic devices, ownership of a personal device, and the type of device used (Figure 3).

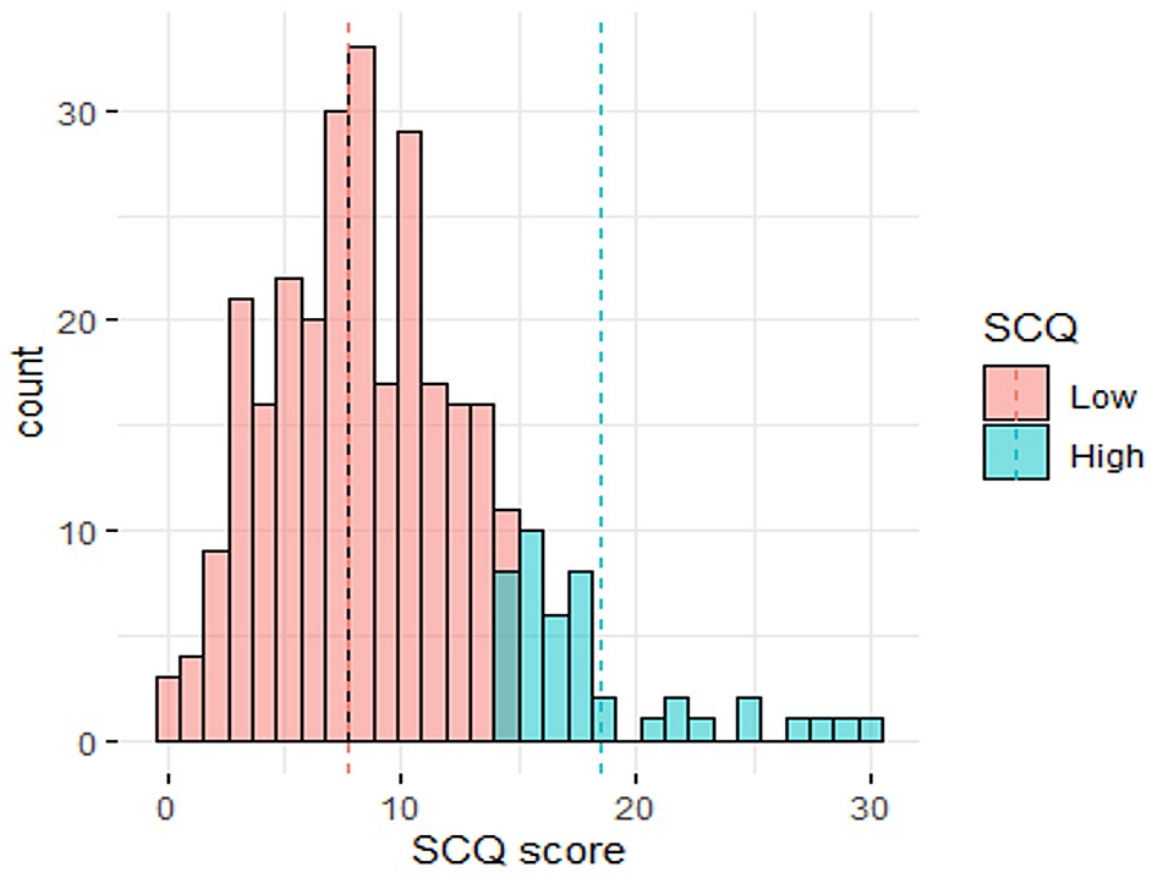

FIGURE 3: Distribution of SCQ scores.

SCQ: Social Communication Questionnaire 


\section{Cureus}

The results showed that the hours spent using the electronic device were significantly associated with having an SCQ score $\geqslant 15(\mathrm{P}<0.05)$. A high SCQ score was prevalent in $19.7 \%(\mathrm{n}=31)$ of children who spent $>3$ hours using the electronic device compared to $10.2 \%(\mathrm{n}=5)$ and $7.84 \%(\mathrm{n}=8)$ of children who spent an hour or less and 2 hours using the electronic device, respectively. The marital status and education of the caregiver showed a significant association with a high SCQ score, although the association was significant at the $10 \%$ level only. The age and gender of the child were not significantly associated with an SCQ score 》 15 (Table 2). 


\section{Cureus}

\begin{tabular}{|c|c|c|c|}
\hline & Low & High & $\mathbf{P}$ \\
\hline & $\mathrm{N}=264$ & $\mathrm{~N}=44$ & \\
\hline Age: & & & 0.541 \\
\hline Five years & $72(88.9 \%)$ & $9(11.1 \%)$ & \\
\hline Four years & $89(83.2 \%)$ & $18(16.8 \%)$ & \\
\hline Six years & $103(85.8 \%)$ & $17(14.2 \%)$ & \\
\hline Sex: & & & 0.191 \\
\hline Female & $109(89.3 \%)$ & $13(10.7 \%)$ & \\
\hline Male & $155(83.3 \%)$ & $31(16.7 \%)$ & \\
\hline Marital status of the caregiver: & & & 0.063 \\
\hline Parents live in the same house & $244(86.2 \%)$ & $39(13.8 \%)$ & \\
\hline Separated & $17(89.5 \%)$ & $2(10.5 \%)$ & \\
\hline Widowed & $3(50.0 \%)$ & $3(50.0 \%)$ & \\
\hline Education level of the caregiver: & & & 0.092 \\
\hline Bachelor's degree & $165(84.6 \%)$ & $30(15.4 \%)$ & \\
\hline High school & $21(80.8 \%)$ & $5(19.2 \%)$ & \\
\hline Middle school & $2(66.7 \%)$ & $1(33.3 \%)$ & \\
\hline Post-graduate degree & 62 (93.9\%) & $4(6.06 \%)$ & \\
\hline Primary school & $14(77.8 \%)$ & $4(22.2 \%)$ & \\
\hline Electronic device usually used by the child: & & & 0.234 \\
\hline Mobile phone & $70(87.5 \%)$ & $10(12.5 \%)$ & \\
\hline Other & $20(90.9 \%)$ & $2(9.09 \%)$ & \\
\hline Tablet/iPad & $100(80.6 \%)$ & $24(19.4 \%)$ & \\
\hline Television & $74(90.2 \%)$ & $8(9.76 \%)$ & \\
\hline Does the child have a personal device? & & & 0.595 \\
\hline No & $99(88.4 \%)$ & $13(11.6 \%)$ & \\
\hline Shares with the family & $52(83.9 \%)$ & $10(16.1 \%)$ & \\
\hline Yes & $113(84.3 \%)$ & $21(15.7 \%)$ & \\
\hline Daily hours spent using the electronic device: & & & 0.019 \\
\hline Hour or less & $44(89.8 \%)$ & $5(10.2 \%)$ & \\
\hline Two hours & $94(92.2 \%)$ & $8(7.84 \%)$ & \\
\hline More than three hours & $126(80.3 \%)$ & $31(19.7 \%)$ & \\
\hline
\end{tabular}

\section{TABLE 2: Factors associated with high SCQ scores}

Note. Counts and percentages were used to summarize the distribution of categorical variables. Statistical analysis was performed using a chi-square test of independence. SCQ, Social Communication Questionnaire

Linear regression (Table 3) was used to examine the factors associated with high SCQ scores (as a continuous variable). So the linear regression analysis showed that gender was significantly associated with the average 


\section{Cureus}

SCQ score $(\mathrm{B}=1.37, \mathrm{P}<0.05)$, indicating that the average SCQ score is higher by 1.37 points in males than females. Age did not show any significant association with the SCQ score. The time spent using the electronic device was significantly associated with the average SCQ score $(B=1.3, P<0.05)$, which indicates that the average SCQ score is higher by 1.3 points in respondents who spent $\geqslant 3$ hours daily using the electronic device than respondents who used the electronic device for $<3$ hours daily (Table 3).

\begin{tabular}{|c|c|c|c|}
\hline \multirow[b]{2}{*}{ Predictors } & \multicolumn{3}{|l|}{ SCQ score } \\
\hline & Estimates & $\mathrm{Cl}$ & $p$ \\
\hline (Intercept) & 11.44 & $9.21-13.67$ & $<0.001$ \\
\hline Sex: Female & \multicolumn{3}{|l|}{ Reference } \\
\hline Sex: Male & 1.37 & $0.23-2.51$ & 0.019 \\
\hline Caregivers' Marital status: Married & \multicolumn{3}{|l|}{ Reference } \\
\hline Marital status: Separated & -1.90 & -4.22 to 0.42 & 0.108 \\
\hline Marital status: Widowed & 4.64 & $0.58-8.69$ & 0.025 \\
\hline Electronic device usually used: Mobile & \multicolumn{3}{|l|}{ Reference } \\
\hline Electronic device usually used: Other & -0.01 & -2.46 to 2.43 & 0.992 \\
\hline Electronic device usually used: Tablet/iPad & 0.06 & -1.38 to 1.49 & 0.940 \\
\hline Electronic device usually used: Television & -0.25 & -1.84 to 1.33 & 0.756 \\
\hline Child has a personal device: No & \multicolumn{3}{|l|}{ Reference } \\
\hline Child has a personal device: Shares with the family & 0.76 & -0.87 to 2.38 & 0.360 \\
\hline Child has a personal device: Yes & 0.59 & -0.82 to 2.01 & 0.410 \\
\hline Age: Four years & \multicolumn{3}{|l|}{ Reference } \\
\hline Age: Five years & -0.92 & -2.37 to 0.54 & 0.217 \\
\hline Age: Six years & -0.76 & -2.13 to 0.62 & 0.278 \\
\hline Caregivers' Education: Bachelor's degree & \multicolumn{3}{|l|}{ Reterence } \\
\hline Education: High school or less & -0.29 & -1.94 to 1.35 & 0.725 \\
\hline Education: Post-graduate degree & -1.27 & -2.67 to 0.13 & 0.075 \\
\hline \multicolumn{4}{|l|}{ Daily time spent on the device: $<3 \mathrm{~h}$} \\
\hline Daily time spent on device: $\geq 3 \mathrm{~h}$ & 1.30 & $0.14-2.45$ & 0.028 \\
\hline
\end{tabular}

TABLE 3: Factors associated with high SCQ scores

SCQ: Social Communication Questionnaire

\section{Discussion}

This study aimed to investigate and provide a new insight into the relationship between prolonged electronic device exposure and autism-like symptoms based on the assumption that excessive use of electronics may lead to ASD-like symptoms. A self-administered questionnaire containing the Social Communication Questionnaire scale (SCQ) was used for preschool children, and other variables added including a question about the hours spent on devices by children.

The results indicate that most of the children used electronic devices for $>3$ hours daily. Surprisingly, the study highlighted a significant association between the daily hours spent on devices and having an SCQ score above 15 , which suggests that children using electronic devices for $>3$ hours daily may suffer from ASD-like symptoms, indicating the need for further comprehensive clinical evaluation to confirm the diagnosis. Additionally, the results show that the average SCQ score is higher in participants using the electronic devices for $>3$ hours even if they did not reach the cut-off point of an SCQ score $=15$. However, the type of association - causation or coincidence - has not yet been established. 
A cohort study of 2152 children was conducted to determine the association between screen time exposure in the first 18 months of life and the development of ASD-like symptoms using the Modified Checklist for Autism in Toddlers (M-CHAT) at two years. This study showed that screen time exposure early in life can be associated with ASD-like symptoms [18]. Interestingly, previous studies concluded that ASD children have a remarkable attraction to screen viewing at a younger age compared to their healthy peers. This is explained by their nature of having less social leisure [19] and preference for computing activity over social network browsing because it is very demanding for them to be socially engaged [20].

Moreover, previous research has proven that the severity of ASD symptoms is proportionate to screen time, clearly recognized in atypical sensory responsiveness and greater susceptibility to developmental delay, specifically in the language domain [21]. Simultaneously, the reverse casualty must be considered. Our data failed to show a significant relationship between an SCQ score above 15 and the marital status and education of the caregiver or the age and gender of the child. Contrary to our expectations, although the majority of the participants' caregivers was well educated and expected to be aware of the risk of overexposure, most of the children had personal devices, with the tablet being the most common. Therefore, it is crucial to emphasize the risk and benefits of these electronic gadgets.

In line with our hypothesis, a large-scale study conducted in Korea on toddler children to determine the effect of screen time on language development through multiple interviews and questionnaires found that language delay is proportional to screen time, with a 2.7 times greater risk for those who spend 2 hours of watching television [22]. The reliability of this data is impacted by several factors.

\section{Limitations}

First, data was collected during the COVID-19 pandemic when all schools and kindergartens had shifted to virtual classes and activities. Second, this study was subject to reporter bias as it relies on caregiver recall. Third, our study was limited to caregiver who uses social media.

\section{Conclusions}

This study has shown that there is a significant association between daily hours spent on devices especially three hours and more and having an SCQ score above 15, which may suggest a possible ASD-like symptoms. However, the type of association has not yet been established. Our findings can be used to raise awareness on this matter and help set guidelines on the use of media for children. Future studies are required to assess association.

\section{Additional Information Disclosures}

Human subjects: Consent was obtained or waived by all participants in this study. Al-Imam Mohammad Ibn Saud Islamic University issued approval HAPO-01-R-001. Animal subjects: All authors have confirmed that this study did not involve animal subjects or tissue. Conflicts of interest: In compliance with the ICMJE uniform disclosure form, all authors declare the following: Payment/services info: All authors have declared that no financial support was received from any organization for the submitted work. Financial relationships: All authors have declared that they have no financial relationships at present or within the previous three years with any organizations that might have an interest in the submitted work. Other relationships: All authors have declared that there are no other relationships or activities that could appear to have influenced the submitted work.

\section{Acknowledgements}

The authors would like to thank and acknowledge all parents who consented their child to participate in the study as well as the children themselves. Also we would like to thank wordvice for the editing of the manuscript of our research.

\section{References}

1. Robinson TN, Banda JA, Hale L, Lu AS, Fleming-Milici F, Calvert SL, Wartella E: Screen media exposure and obesity in children and adolescents. Pediatrics. 2017, 140:S97-S101. 10.1542/peds.2016-1758K

2. Lissak G: Adverse physiological and psychological effects of screen time on children and adolescents: literature review and case study. Environ Res. 2018, 164:149-157. 10.1016/j.envres.2018.01.015

3. Radesky JS, Christakis DA: Increased screen time: implications for early childhood development and behavior. Pediatr Clin North Am. 2016, 63:827-839. 10.1016/j.pcl.2016.06.006

4. American Academy of Pediatrics announces new recommendations for children's media use . (2016). Accessed: October 21, 2016: https://services.aap.org/en/news-room/news-releases/aap/2016/aapannounces-new-recommendations-for-media-use/.

5. World Health Organization: Guidelines on Physical Activity, Sedentary Behaviour and Sleep for Children Under 5 Years of Age. World Health Organization, 2019.

6. CDC's developmental milestones. (2021). Accessed: October 14, 2021: https://www.cdc.gov/ncbddd/actearly/milestones/index.html. 
7. Scharf RJ, Scharf GJ, Stroustrup A: Developmental milestones. Pediatr Rev. 2016, 37:25-38. 10.1542/pir.2014-0103

8. Hinkley T, Brown H, Carson V, Teychenne M: Cross sectional associations of screen time and outdoor play with social skills in preschool children. PLoS One. 2018, 13:e0193700. 10.1371/journal.pone.0193700

9. MacGowan TL, Schmidt LA: Preschoolers' social cognitive development in the age of screen time ubiquity . Cyberpsychol Behav Soc Netw. 2021, 24:141-144. 10.1089/cyber.2020.0093

10. Wu X, Tao S, Rutayisire E, Chen Y, Huang K, Tao F: The relationship between screen time, nighttime sleep duration, and behavioural problems in preschool children in China. Eur Child Adolesc Psychiatry. 2017, 26:541-548. 10.1007/s00787-016-0912-8

11. Chen JY, Strodl E, Wu CA, et al.: Screen time and autistic-like behaviors among preschool children in China . Psychol Health Med. 2021, 26:607-620. 10.1080/13548506.2020.1851034

12. Ikeda K, Nakamura K: Association between mobile phone use and depressed mood in Japanese adolescents: a cross-sectional study. Environ Health Prev Med. 2014, 19:187-193. 10.1007/s12199-013-0373-3

13. Amawi SO, Subki AH, Khatib HA, Alkhateeb OS, Fida RH, Saggaf OM, Jan MM: Use of electronic entertainment and communication devices among a Saudi pediatric population: cross-sectional study. Interact J Med Res. 2018, 7:e13. 10.2196/ijmr.9103

14. Alobaid L, BinJadeed H, Alkhamis A, Alotaibi R, Tharkar S, Gosadi I, Gad A: Burgeoning rise in smartphone usage among school children in Saudi Arabia: baseline assessment of recognition and attention skills among users and non-users using CANTAB tests. Ulutas Med J. 2018, 4:4-11. 10.5455/umj.20180203121836

15. Madigan S, McArthur B, Anhorn C, Eirich R, Christakis DA: Associations between screen use and child language skills: a systematic review and meta-analysis. JAMA Pediatr. 2020, 174:665-675. 10.1001/jamapediatrics.2020.0327

16. American Psychiatric Association: Diagnostic and Statistical Manual of Mental Disorders (DSM-5) . American Psychiatric Publishing, 2021.

17. Aldosari M, Fombonne E, Aldhalaan H, et al.: Validation of the Arabic version of the Social Communication Questionnaire. Autism. 2019, 23:1655-1662. 10.1177/1362361318816065

18. Heffler KF, Sienko DM, Subedi K, McCann KA, Bennett DS: Association of early-life social and digital media experiences with development of autism spectrum disorder-like symptoms. JAMA Pediatr. 2020, 174:690696. 10.1001/jamapediatrics.2020.0230

19. Slobodin O, Heffler KF, Davidovitch M: Screen media and autism spectrum disorder: a systematic literature review. J Dev Behav Pediatr. 2019, 40:303-311. 10.1097/DBP.0000000000000654

20. MacMullin JA, Lunsky Y, Weiss JA: Plugged in: electronics use in youth and young adults with autism spectrum disorder. Autism. 2016, 20:45-54. 10.1177/1362361314566047

21. Dong HY, Wang B, Li HH, Yue XJ, Jia FY: Correlation between screen time and autistic symptoms as well as development quotients in children with autism spectrum disorder. Front Psychiatry. 2021, 12:619994. 10.3389/fpsyt.2021.619994

22. Byeon H, Hong S: Relationship between television viewing and language delay in toddlers: evidence from a Korea national cross-sectional survey. PLoS One. 2015, 10:e0120663. 10.1371/journal.pone.0120663 